\title{
Using Mathematical Modeling for Integrating STEM Disciplines: A Theoretical Framework
}

\author{
Muhammed Fatih Doğan ${ }^{a}$, Ramazan Gürbüz ${ }^{b}$, Zeynep Çavuş-Erdem ${ }^{c}$ and \\ Seda Şahin ${ }^{\text {d }}$
}

aAdıyaman University, Faculty of Education, Adıyaman/Türkiye (ORCID: 0000-0002-5301-9034)
bAdıyaman University, Faculty of Education, Adıyaman/Türkiye (ORCID: 0000-0002-2412-5882)
${ }^{\mathbf{b}}$ MEB, Mehmet Akif Ersoy Ortaokulu, Adıyaman/Türkiye (ORCID: 0000-0002-7448-2722)
${ }^{\mathbf{b}}$ Adıyaman University, Faculty of Education, Adıyaman/Türkiye (ORCID: 0000-0003-3202-8852)

Article History: Received: 25 December 2018; Accepted: 26 November 2019; Published online: 3 December 2019

\begin{abstract}
The main goal of STEM education is to provide students with knowledge and skills in science, technology, mathematics, and engineering through interdisciplinary approaches. However, perspective on the nature of STEM approaches and how it should be implemented in the classrooms without losing discipline integrity are still not uncovered and stay as important challenges for both educators and researchers. In this paper, we introduce a theoretical framework that can shed light on how to engage students effectively in STEM education by providing mathematical modeling as a tool for integrating different disciplines. Thus, this framework is for designing, implementing, and evaluating mathematical modeling thinking within an interdisciplinary nature. Furthermore, we provide an example of the interdisciplinary mathematical modeling task with hypothetical student engagement in the process and analyzed the student's thinking with our framework. Although the focus of this paper is mainly about integrating mathematics and science, we believe that our framework can be applied to all STEM disciplines. We conclude that interdisciplinary mathematical modeling framework might be an important tool to overcome some of the challenges that stressed in the literature since it increases the transfer capacity of STEM-focused knowledge and skills to real-world scenarios by presenting problem situations in a real-world context.
\end{abstract}

Keywords: Interdisciplinary mathematical modeling, mathematical modeling, Mathematics and Science Education, STEM education, STEM integration

DOI: $10.16949 /$ turkbilmat.502007

\section{Introduction}

The school mathematics curricula emphasize learning of mathematics as a process that requires students' active participation in their learning, where they can research and inquire, communicate, think critically, engage in reasoning, share ideas easily and offer different solutions (Common Core State Standards for Mathematics [CCSSM], 2011; Ministry of National Education [MoNE], 2018). In their mathematics programs, students are expected to gain different skills such as critical thinking, problem posing, problem solving, reasoning, collaborating, and communicating. As Wagner (2014) highlights, Science, Technology, Engineering, and Mathematics (STEM) education aims similar skills such as critical thinking and problem solving, collaboration across networks, agility and

* This research was supported by the Scientific and Technological Research Council of Turkey (TUBITAK) under grant 117 K169. The views expressed do not necessarily reflect the official positions of the TUBITAK.

Citation information: Doğan, M. F., Gürbüz, R., Çavuş-Erdem, Z., \& Şahin, S. (2019). Using mathematical modeling for integrating STEM disciplines: A theoretical framework. Turkish Journal of Computer and Mathematics Education, $10(3), 628-653$. 
adaptability, initiative and entrepreneurialism, effective communication, accessing and analyzing information, and curiosity and imagination. These skills are sometimes called as 21 st century skills (Partnership for 21 st Century Skills, 2015) and many organizations and educators have argued that students must develop those skills to be effective in their posteducation lives and work-places (Bowman, 2010; Marginson, Tytler, Freeman \& Roberts, 2013; Fitzallen, 2015). Therefore, STEM might provide an effective learning environment for students to acquire both mathematical and $21^{\text {st }}$-century skills. However, it is not clear how $21^{\text {st }}$-century skills might be pursued in mathematics education (Gravemeijer, Stephan, Julie, Lin \& Ohtani, 2017). In other words, one important question is what STEM education may have to offer for mathematics education, and vice versa. Fitzallen (2015) sees the recent emphasis on STEM education as an opportunity for innovation and change in mathematics classrooms. We agree with her and propose that using mathematical modeling $(\mathrm{MM})$ as a tool for integrated STEM education can be a fruitful avenue for the field. Even though the relevant literature highlights the importance of mathematics in STEM education and sees MM as an important tool for creating opportunities to engage students in STEM activities, it is not well discussed that how MM can be used for this specific purpose. The literature lacks, specifically, on explaining how to teach mathematics and other STEM disciplines together and how to integrate these different subjects in modeling activities to enhance students' learning. Here we offer a theoretical framework paired with an example from a STEM project that will both support the development of mathematical ideas and concepts and exemplify how mathematics can influence and contribute to the understanding of the ideas and concepts of other STEM disciplines. In the following sections, we will first discuss STEM and Mathematical Modeling, and then present our framework that uses mathematical modeling to integrate STEM education by focusing on Mathematics and Science disciplines. Finally, we will provide an example of how to use our framework to enhance student learning.

\subsection{Literature Review}

STEM is an acronym for the four independent disciplines of science, technology, engineering, and mathematics, and has become increasingly familiar throughout the world due to the thousands of programs launched to produce more science, technology, engineering and mathematics professionals. Lawrenz, Gravemeijer, and Stephan (2017) discuss STEM for the future and the future of STEM (p. 1; italics original) and states that a strong understanding of STEM is key to the successful future. They highlight that:

In the future of STEM, the emphasis is on building on what we know, and how we can use new technologies and teaching approaches to improve STEM education. The goal is of course also to prepare students for their future, but the future itself does not seem to be leading. In STEM for the future, it is the future that is leading and the central question is, what do we need to do to interact effectively with and to help shape that future?

This introduces an important challenge, namely, how we can help our students engage 
effectively in STEM education. English (2017) states that since there is no common understanding of STEM education, having a multitude of perspectives on STEM education makes it hard to know what STEM entails and to have a systematic way of enactment of STEM curriculums. She argues that it is important to have well-defined approaches to integrate different STEM disciplines and addresses the unbalanced representation of STEM disciplines in the instruction. In a similar vein, Bybee (2013) states:

The meaning or significance of STEM is not clear and distinct. There is a reference to four disciplines, but sometimes the meaning and emphasis only include one discipline. In some cases, the four disciplines are presumed to be separate but equal. Other definitions identify STEM education as an integration of the four disciplines. (p. $x$ )

Based on Bybee's insight and as the name suggested and by its nature, we consider STEM to be an interdisciplinary approach (Smith \& Karr-Kidwell, 2000; Treacy \& O'Donoghue, 2014; Galili, 2018). This approach emphasizes the link between disciplines "so that learning becomes connected, focused, meaningful, and relevant to learners" (Smith \& Karr-Kidwell, 2000, p. 24). Shaughnessy (2013) sees STEM education as solving problems related to the concepts and procedures of mathematics and science by incorporating appropriate engineering and technology concepts. This interdisciplinary approach raises the question of how to integrate different independent disciplines. Treacy and O'Donoghue (2014) suggested Authentic Integration as an interrelated approach, particularly for mathematics and science but applicable to all STEM subjects. The main purpose of this approach is to promote meaningful learning, by ensuring that any tasks, problems, and activities have standards for intellectual quality. Authentic integration includes four main characteristics: knowledge development, synthesis and application; focused inquiry resulting in higher-order learning; application to real-world scenarios; and rich tasks (Figure 1). Although the authentic integration approach is appropriate for all of the STEM disciplines, it is particularly appropriate for this paper, in part because our current emphasis is on mathematics and science through mathematical modeling. It is important to state that making connections across all the disciplines collectively in STEM education is not necessary; having connections among any two or more STEM disciplines is sufficient to have an integrative approach (Sanders, 2009).

Knowledge development, synthesis, and application refer to students' use of their previous knowledge in both domains (mathematics and science) to improve and enhance their knowledge and then synthesize this knowledge and apply it to a new situation. Here, students need to identify and use the connections between the concepts they develop in both disciplines, which will enable them to use this knowledge in other areas of education and real-life scenarios. Thus, knowledge from various domains must be accumulated and combined effectively by having an integration that combines concepts and principles from both domains which overlap in a meaningful manner. 


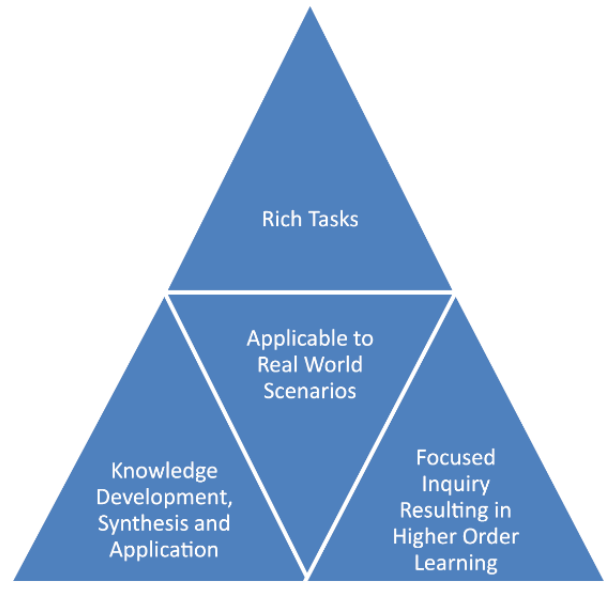

Figure 1. The authentic integration triangle (Reproduced from Treacy \& O'Donoghue, 2014, p. 710)

Focused inquiry resulting in higher-order learning refers to having purposeful discussions that allow students to develop and demonstrate their knowledge of the concepts being studied in both mathematics and science. This way, students have opportunities to engage in higher-order thinking and enhance their learning in both subjects. Thus, having scenarios that students can relate to their own experiences may allow students to develop a more robust understanding of mathematics and science concepts. In the authentic integration triangle, the characteristic of being applicable applicable to real-world scenarios is based on realistic mathematics education and refers to the importance of making connections between school learning and everyday life. The last characteristic of the model is rich tasks that refers to problem-based challenges that require students to attend both mathematics and science concepts together. Thus, these rich tasks are transdisciplinary and provide opportunities for developing knowledge and higher-order thinking. MM tasks might count as rich tasks that can be applicable to real-world scenarios as they can be designed to integrate both mathematics and science concepts. Thus, we believe the authentic integration approach aligns with using MM as a tool for STEM education.

Fitzallen (2015) notes that the authentic integration model can be applied to both the individual STEM disciplines and the integrative notion of STEM education. Thus, the model is a purposeful and useful way of integrating STEM disciplines. For this study, this model will be used for identifying and applying the interdisciplinary nature of STEM education.

Since the STEM approach aims to strengthen the learning and transfer of knowledge by uncovering relations between school education and students' daily life, a number of researchers and stakeholders (e.g., Berry, Chalmers \& Chandra, 2012; Ostler, 2012; Moore 
\& Smith, 2014; Fitzallen, 2015; MoNE, 2016) advocate for an integrative STEM education in order to achieve its primary purpose that is connecting students' learning with real-life situations. STEM education offers considerable opportunities for learning and teaching mathematics because it is associated with everyday life. As such, when looking at mathematics education, STEM encourages the use of activities that can lead to a meaningful context in learning mathematics, which is linked to real-world problems and allows students to actively work on problems (Treacy \& O'Donoghue, 2014). However, the literature shows that there may be an unbalanced representation between four STEM disciplines during instruction; especially the role of mathematics is underrated in STEM education. Mathematics, generally, has been seen as a discipline supporting other disciplines in STEM education (Schmidt \& Houang, 2007) and often remain on the second plan, as an important tool and language for Science, Technology, and Engineering. As stated by Shaughnessy (2013), if mathematics is not given enough attention, it will remain silent in STEM integration. English (2017) specifically focuses on the underrepresentation of Mathematics (M) and Engineering (E) in STEM instruction and advocates more attention for M and E to have an effective STEM education. Since there are many opportunities for students to improve their mathematical skills in STEM education, there should be more emphasis on Mathematics in STEM (e.g., Fitzallen, 2015; English, 2017). In this paper, we will introduce an interdisciplinary framework that might provide meaningful opportunities for students to engage in STEM-related activities. We conjecture that Mathematical Modelling can be used not only as a tool for integrating STEM approach but also for enhancing the role of mathematics in STEM. Thus, we propose an interdisciplinary mathematical modeling approach that facilitates in-depth learning of and about STEM by focusing on mathematics and science.

\section{Theoretical Framework: Interdisciplinary Mathematical Modeling}

Mathematical modeling is the process connecting mathematics and real-life by using mathematical skills (Lesh \& Doerr, 2003) where the starting point is a real-world situation. The problem solver expresses this real-life situation in a more comprehensible way (Blum \& Niss, 1991) by simplifying, structuring, and subjecting it to appropriate conditions and assumptions. The mathematical model includes the relationship between real problem situations and their mathematical representations (Niss, 1989; Blum \& Niss, 1991). In other words, the mathematical model is the external representation of the modeling process (Lesh \& Doerr, 2003). Blum and Niss (1991) call the process of transferring the real-life situation into mathematical language a mathematical process. The modeling process is complex and should not be perceived simply as a simplification of the real-life situation. The mathematical modeling process involves a mental process in which the real-life problem is mathematically solved and the resulting solution is the cognitive activities in which the context and the real world/life are constructed, interpreted, and evaluated (Berry \& Houston, 1995; Lesh \& Doerr, 2003). Some studies have focused on the modeling process steps (Kapur, 1982; Mason, 1988) while others focused on the cognitive characteristics that emerged in the transition to the steps (Berry \& Houston, 1995; Blum, 2011; Borromeo- 
Ferri, 2006; Blomhøj \& Jensen, 2007; Doerr, 1997). Although some of these studies suggest that the modeling process involves a linear process (Kapur, 1982; Mason, 1988), the current approach to the modeling process has been handled in a cyclic manner (Blomhøj \& Jensen, 2007; Blum, 2011; Borromeo-Ferri, 2006). In this study, the mathematical modeling process is accepted as a cyclical process including understanding the problem, constructing the model, solving the model, transforming, evaluating and reporting steps.

Some researchers found that in mathematical modeling activities students can only use limited knowledge of the real world in the process of applying their mathematical decisions ( Verschaffel, Greer \& De Corte, 2000; Ng, 2011). This can lead students to develop some incorrect beliefs about the nature of mathematics and to see mathematics independent from the real world. Despite the activities aimed at gaining more meaningful learning experiences for students, encountering such results is an indication that the gap between school mathematics and the real world is not closed in the curriculum $(\mathrm{Ng}, 2011)$. However, the linkage of mathematics to real-life is considered as a process skill that many countries acquire in their mathematics curriculum (e.g., the National Council of Teachers of Mathematics [NCTM], 2000; Curriculum Planning and Development Division [CPDD], 2006; MoNE, 2016). Real-life, especially science (physics, chemistry, biology),s the basic element of mathematical modeling. Therefore, mathematical modeling can be used as an interdisciplinary learning tool. Particularly, a realistic perspective to the mathematical modeling emphasizes mathematical modeling and modeling of real-life situations and interdisciplinary approaches. The realistic viewpoint regards mathematical modeling as a problem solving activity that plays an important role in different disciplines (Kaiser \& Sriraman, 2006). The mathematics lessons in which modeling and its applications are linked to other disciplines are arguably more compelling and less predictable for students than traditional mathematics lessons. Many students prefer to solve routine problems rather than non-routine problems because it is much easier to understand these problems and it is often enough to follow only certain steps to achieve the solutions (Blum \& Niss, 1991). However, being aware of the relationships among disciplines allows students to see what they are learning about their current or future life (Chan, 2001). Indeed, science can enhance students' learning, motivation, and understanding with concrete examples of abstract mathematical ideas, while mathematics can enable students to achieve a deeper understanding of science concepts by providing ways to quantify science relationships (McBride \& Silverman, 1991).

In mathematics and science teaching, the interpretation and understanding of the subject matter are often held in front of the conceptual understanding. By integrating these disciplines, it is possible to create more meaningful learning environments for students. The integration of mathematics and science disciplines provides a more realistic learning experience and allows students to apply mathematics to real-life situations and situations that are meaningful in their world (Davison, Miller \& Metheny, 1995). The fact that mathematical modeling has a problem-solving approach that is suitable for use in combination with the knowledge of different disciplines allows for as many different 
disciplines as mathematics teaching to be used as an effective tool in teaching science. Mathematical modeling activities enable students to create, deepen, improve or revise the conceptual structures of STEM education disciplines (Lesh \& Doerr, 2003; Uhden, Karam, Pietrocola, \& Pospiech, 2012). Thus, mathematical modeling has an important place in STEM education because students can improve their problem solving skills and their ability to make judgments and communicate in a scientific and mathematical sense. Within the use of mathematical modeling as an interdisciplinary teaching approach, the modeling becomes a more comprehensive and complex process, depending on the characteristics of the disciplines integrated. However, there has not yet been a study describing this process in the literature. For this reason, we developed a theoretical framework for the INTERDISCIPLINARY MATHEMATICAL MODELING [IMM] process (see Figure 2). The IMM fits in the Authentic Integration model suggested by Treacy and O'Donoghue (2014) and uses each component of their model. We designed interdisciplinary mathematical modeling tasks, which are based on real-world scenarios and are transdisciplinary, to have focused inquiry to develop and enhance student learning in both mathematics and science concepts.

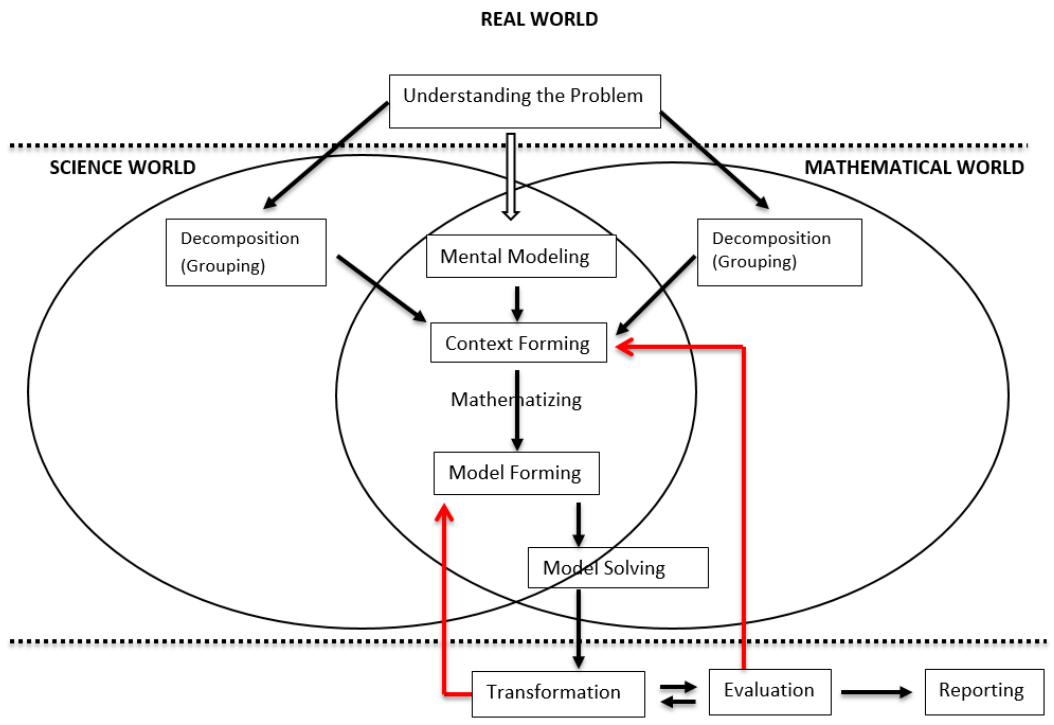

REAL WORLD

Figure 2. Interdisciplinary Mathematical Modeling [IMM] process of Mathematics and Science

We illustrate our model initially by describing the IMM process of Mathematics and Science that directly guided our curriculum development. The theoretical framework shows 
the cognitive process of problem solving in the solution of IMM activities. The current research focuses on two main disciplines in STEM, mathematics and science, and the steps involved in the IMM process given in Figure 2 occur between the subject areas in the presented problem. Thus, in an IMM problem involving mathematics and science, the problem solver performs the decomposition step in two separate areas and then goes to the step of establishing context by doing the same process for each. The modeling process that will take place in an IMM event addressing mathematics and science is given below.

In the IMM process starting in the real world, learners first need to identify the problem situation, in this case, the real-life problem is in between two disciplines mathematics and science (understanding the problem). This step, understanding the problem, is where the world of STEM is introduced. Necessary and unnecessary variables are distinguished in the step of understanding the problem and the problem is simplified by determining the related variables. After determining what is given in the problem and what is desired, the problem solver/individual produces ideas/hypotheses for a solution and makes appropriate plans (creating a mental model). Simplified concepts in the problem are passed through a filter in the mind of the individual and are separated by relating to the relevant discipline (parsing/grouping). The decomposition (grouping) step occurs at the specific position of each discipline. This is because the individual identifies the concept of the area involved in the IMM activity by passing it through the knowledge circulation and then makes a transition to the world of that area cognitively. With this short-lived transition, the individual recognizes the complementary aspects and relationships of the concepts that he or she segregates and connects them back to the common area (STEM) that makes the necessary connections. Context establishment may not occur at the same time in all areas involved in the problem. After the association is made, the problem solver goes to the model building step, which transforms the model created in the mind into a mathematical form. At this stage, the individual mathematizes the problem and creates a mathematical model to solve the problem. After determining the model, the problem solver provides a mathematical solution of the model by using her/his mathematical information (solving the model). Due to the use of mathematical structures and operations, this step is in the world of mathematics but uses information from other fields as well. The problem solver thinks of the result obtained after solving the model of real-life (transformation) and tests the validity of the solution and its applicability in real life (evaluation). After convincing that the model created is functional in real life, the problem solver will prepare a report that summarizes the problem-solving process and results of the problem (report).

There is a flexible transition between all steps in the theoretical framework of the IMM process. For example, if the problem solver finds that his/her model does not fit its counterpart in the real world, or that it cannot be applied to the real world, s/he may switch from transformation step or evaluation step to model forming or higher steps such as problem understanding. The problem solvers complete the modeling process with reporting their reasoning behind thir model, which is the last step by experiencing the same process from the moment it returns. The flexibility between the steps suggests that the problem 
solver can move forward by skipping some steps. For example, in the step of understanding the problem, it is possible to switch to the mental model building stage without separating the concepts according to the disciplines.

It is important to highlight that our framework is for designing, implementing, and evaluating modeling thinking within an interdisciplinary nature. Below we provide an example of how IMM can be effectively used to enhance STEM education. First, we will introduce an IMM activity- Electricity from the Sun-that emphasizes both Mathematics and Science disciplines. Then, we will show how a secondary student might approach this problem and solve it. Finally, we will analyze the potential student response based on the IMM framework.

The activity of Electricity from the Sun aims to enhance students' understanding in both mathematics and science subjects by providing a real-world based scenario as a rich task (the full problem is in Appendix A). The activity starts with warm up questions, whose goal is to prepare students for the main activity by doing research and developing pre-knowledge (prerequisite knowledge) for engaging in a meaningful discussion. For that purpose, students will be given the following questions before class time:

- For what purposes can we use solar energy?

- Is it possible for you to convert solar energy into electricity? (If the answer is "yes") How?

After having the opportunity of researching solar energy, students will discuss relevant science concepts in the classroom. This will enable students to develop pre-knowledge about the topic.

After having this initial discussion in the classroom, the students will be given the text/news that has information about solar energy to develop a common knowledge on the topic to make sure that all the students have the required knowledge to understand and solve the problem. 


\section{The Solar Energy}

With renewable energy sources becoming more important in recent years, solar energy systems, which are an environmentally clean energy source, have started to be used frequently in the production of electricity. Solar energy systems are the systems that turn solar energy into electricity. The full capacity working life of a solar panel is 25 years on average. At the end of this period, it continues to work at $75 \%$ efficiency. To give an example of the amount of electricity produced by panels;

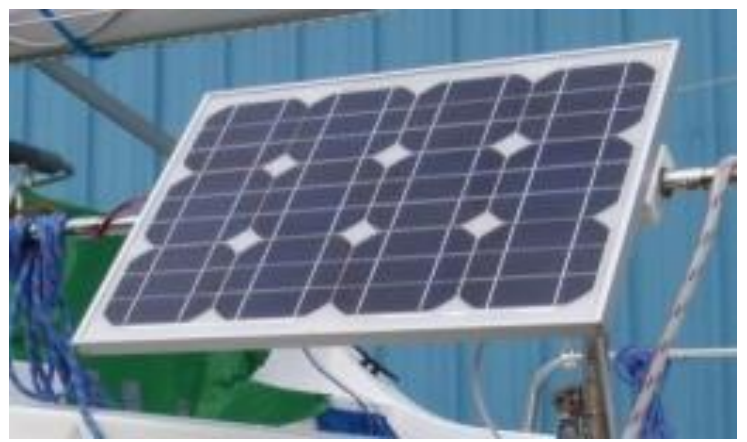

As shown in the figure, a 200 Watt solar energy panel with a size of $70 \mathrm{~cm}$ x $150 \mathrm{~cm}$ takes an average of 6 hours of sunshine per day. In this case, the amount of electricity produced per day is $200 \times 6=1200$ watts.

$$
\text { Power }=\frac{\text { Energy }}{\text { Time }}
$$

Watt is the electrical power unit. Electrical power is the amount of electricity consumed per unit time. The unit of power is watt (w), the unit of energy is joule, the unit of time is assumed to be seconds. The amount of electrical power we spend on household appliances (fridge, oven, etc.), electronics (electricity vacuum, television, etc.) we use in daily life is expressed in watts. Generally, the number written on the vacuum cleaners shows the amount of electrical power that the vacuum consumes in an hour when the vacuum is running. For example, a $1,500 \mathrm{~W}$ cleaner consumes $1.5 \mathrm{~kW}$ of power per hour. In the same way, a 20 -watt bulb that we use in our homes consumes $0.02 \mathrm{~kW}$ per hour.

Electric bills are also calculated over the kilowatt used per month.

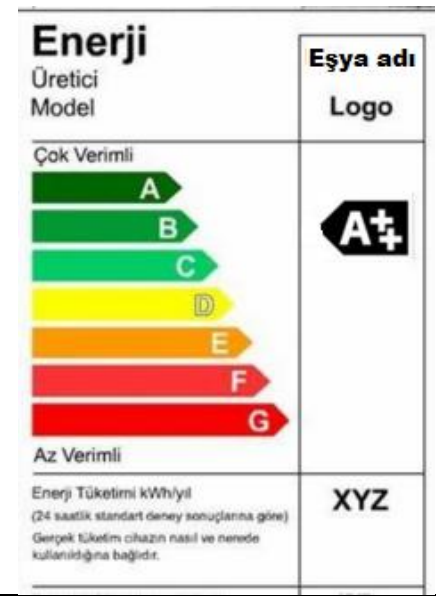

In recent years, along with the advancement of technology, electronic goods are saving energy by consuming less energy without affecting the desired level of service and comfort. The figure on the side labeled "Energy Efficiency Label" divides the annual energy consumption of electronic goods into seven classes named A, B, C, D, E, F and G. The letter A shows the highest energy efficiency and lowest energy consumption. In other words, the consumption class, shown by the letter A consuming at least a watt per hour, does the same job with much less energy than the other classes. For example; a refrigerator with energy efficiency class "A" consumes $23 \%$ less energy than a class $\mathrm{B}$ refrigerator, $45 \%$ less energy than a class D refrigerator, and $56 \%$ less energy than a class $G$ refrigerator. Similarly, the energyefficient "A" class dishwasher provides $32 \%$ energy saving compared to a "D" class dishwasher and $48 \%$ energy saving compared to a "G" class dishwasher. The new consumption classes are called $\mathrm{A}+$ and $\mathrm{A}$ ++ , with energy efficiency being higher than that of the class A electronic goods. 
After reading this text, the student will be asked the following questions as warm up activity for the problem.

- By examining the vacuum cleaner in your home, find the amount of energy that it spends in one second, one minute and one hour.

- Note the unit on top of the electricity meter in your home.

- Write down which consumer class your electronics belong to in your home.

The purpose of having these questions is to make a connection between the task and the students' real-life experiences. Students need to think about the amount of energy consumed per unit time for a vacuum cleaner, the electricity meters that measure energy consumption, and the billing system for energy usage. Thus, these kinds of questions will allow students to scientifically understand a routine activity in their real-life. In the case of the following problem situation, students need to calculate the average electricity consumption and decide whether it is appropriate to install solar panels to a family roof. For this, students must first consider the energy savings when determining the amount of electricity consumed in a given time period (month, year). Then, while choosing the most appropriate option among the solar panels (installation costs, aesthetic appearance, etc.), they are expected to perform various combinations and mathematical concepts such as inequality, area and percentage calculations. Therefore, it is only possible for students to associate science and mathematics disciplines to determine whether an innovative technological application such as solar panel, which will make solar energy applicable in daily life, is mathematically profitable. In this respect, warm up questions are seen as a crucial step for the students to associate science and mathematics disciplines. It is important to note that students will need to develop the required concepts to make sense of the problem. Thus, implementing this kind of tasks may require more than one class time period or day. For example in this problem, the students will need time to collect relevant information to solve the problem before engaging in the main problem situation. Before starting to work on the problem, students should discuss the warm-up questions based on their collected data. After having students collected this information and had a discussion about electric consumption, the problem statement given below will be provided:

Mr. Ahmet wants to build solar panels in a way that can match his electricity needs at a reasonable cost. Panels can store the electricity produced. Create a model that shows how Mr. Ahmet can place the solar panels that can meet his electricity needs at the roof, at an affordable cost, and show in detail how you did it. Do you think that Mr. Ahmet should build solar panels to cover the electricity cost of the house?

This rich task scenario is a problem-based activity that demands developing knowledge from both mathematics and science, synthesizes that knowledge, and applies it to solve the problem by creating a model. Students will have 60-90 minutes to solve and write a report about their model. 
Students will need to work both individually and collectively in the classroom to solve the problem. Here, we present a student's answer to the problem regarding the IMM framework, with the full hypothetical response is in Appendix B. It is important to note that we are not claiming that this hypothetical situation is a representation of hypothetical thinking for the problem. Instead, the answer given here was selected from a few different responses provided by the research team to answer the problem. After selecting the answer, we reorganized the answer to anticipate an ordinary student answer to the problem that we call a hypothetical answer. The main reason doing this is that the modeling is a cyclical process where students start this process at a certain stage according to their preferences and may go back to different stages several times or ignore some stages in the process, which means it might not be possible to identify each stage. On the other hand, in a full modeling process, all stages have a counterpart (Borromeo-Ferri, 2006) and need to represent. Thus, the sample solution examined in this study must include all stages of the modeling process to understand the theoretical framework presented clearly. For this reason, a hypothetical student solution that reflects all the stages of the theoretical framework is chosen and discussed. To provide an example of the IMM framework, an analysis of the hypothetical situations, an imaginary student's (Kerem) answer, is presented below. Yet, again, this could be also done with a group report rather than an individual student.

Understanding the problem. Kerem states that what the problem asks by saying "I want to calculate the amount of electricity Mr. Ahmet wants to find the most saving solar panel model." This shows that he understands the problem.

Decomposition/Grouping. Kerem identifies what he needs to figure out to solve the problem. He says "I have to find out how many $\mathrm{kW}$ of electricity Mr. Ahmet has spent in a given time period. I need to determine how many kilowatts of electricity are needed for electronic goods and lamps on the table in one hour." The first question is directly related to science concepts. Kerem then states that he needs to calculate the total electricity cost, which is directly related to mathematics concepts. Thus, here, Kerem identifies both disciplines and synthesize his knowledge to solve the problem.

Creating a mental model. Kerem makes assumptions about Mr. Ahmet's life such as "I think it's a family of 5" and about solar power such as "Because the days are shorter in winter, the length of use of household lamps will be longer than in summer months". This shows that Kerem has a mental model that provides a path on how to solve the problem. Kerem's mental modeling process is not complete with these statements. After making the assumption, he expresses it mathematically, and then goes back to this stage and continues to make assumptions about modeling. In this cyclical process, at this stage, he has not created a final model yet.

Mathematizing. Kerem then finds the average amount of electricity consumed weekly by the family. He provides mathematical calculations and finds that Mr. Ahmet and his family spend an average of 60440 watts of electricity in a week and converts that to $\mathrm{kW}$ (this is 60000 watts $=60 \mathrm{~kW}$ ). He concludes that the family needs $8.57 \mathrm{~kW}$ electricity in a 
day and states "Now I will choose the most suitable solar panel for the roof". This shows that he mathematized the problem situation and now he needs to create a model to come up with a decision for the family.

Creating a mental model. While developing his model, Kerem considers the shape of the roof to figure out where and how the panels should be placed. He says "For solar energy to be stored at the highest level, the rays of the sun must come at a right angle. If the panel is fixed to the roof, it can store energy at certain times of the day. For this, I am going to use moving panels to raise the level of solar utilization." Here he is still developing his mental model to decide how to locate the panels. He decides to locate the panels on the trapezoidal surface since the solar energies always look south (Transformation). He prefers to use a single panel type for his model because of aesthetic reasons: "having panels of different sizes are ugly on the roof". Kerem has chosen to use one type of solar panel for his model. The reason for this might be his experiences with the use of panels of the same size in the solar panel systems in his real-life (in the neighborhood, on the internet, in books, etc.). Furthermore, even if Kerem thinks that it is possible to use panels of different sizes to locate on the roof, he believes it is not aesthetic and common to have this kind of design.

Model Forming. After having a final mental model, Kerem decides to place the solar panels to the roof as in Picture 1. While locating the panels, he considers the slope of the panels for maximum efficiency and decides to locate panels with a $45^{\circ}$ slope. After deciding on the inclination of the roof, he created a model based on his mathematical calculations above.

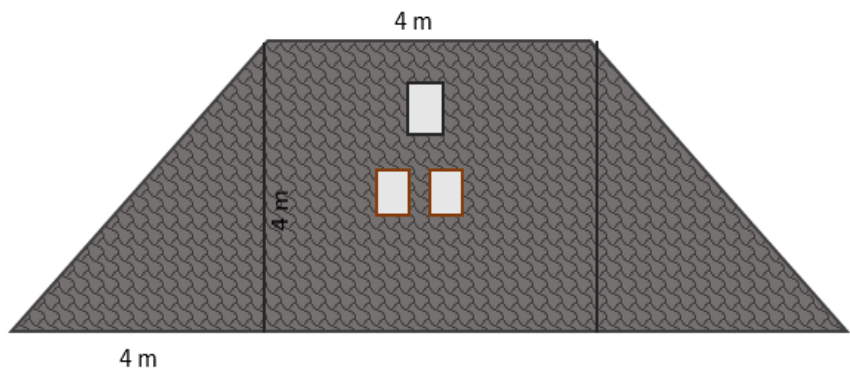

$12 \mathrm{~m}$

\section{Picture 1}

"I have calculated above that the amount of electricity used by Mr. Ahmet and his family is

Brand A: $300 \times 9=2700$ watt,

Brand B: $200 \times 9=1800$ watt and

Brand C: $45 \times 9=405$ watt
$8.57 \mathrm{~kW}=8570$ watts per day. Then I must first find out how many (the minimum number) solar panels I need to use."

$x: 2700 x>8570$ if it is A brand solar panel

y: $1800 y>8570$ if it is B brand solar panel 
$z: 405 z>8570$ if it is $C$ brand solar panel.

Model resolution. After creating his model, Kerem solves his model to decide which brand is the best for Mr. Ahmet and his family.

Kerem: " $x$ must be at least 4; $y$ must be at least 5; z must be at least 22. Looking at the areas of the solar panels, it is seen that the solar panels in these numbers can easily be located on the roof:

A brand: Since $1 m \times 2 m=2 m 2,2 \times 4=8 m^{2}$ area needed

$B$ brand: Since $1 \mathrm{~m} \times 1.5 \mathrm{~m}=1.5 \mathrm{~m}^{2}, 1.5 \times 5=7.5 \mathrm{~m}^{2}$ area needed

$C$ brand: Since $0.55 m \times 0.65 m=0.3575 m^{2}, 0.3575 \times 22=7.865 m^{2}$ area needed.

I can find the solar panel with the highest performance by comparing the price of solar panels, the size and the amount of power produced in one hour...Brand A produces $300 \times 3$ $=900$ watts while brand B produces $200 \times 4=800$ watts of power per hour. In this case, the cost to produce 1 watt of electricity from brand A solar panel $(3750 / 900=4.16 \mathrm{TL})$ is more than brand B solar panel $(3200 / 800=4 T L)$. This means that the performance of the brand $B$ solar panel is higher than brand $A$. A similar calculation shows that the $A$ brand is more affordable than the $C$ brand. Thus, we can sort the panels by $B>A>C$., In that case, it would be more advantageous to use the B brand panel."

Thus, based on Kerem's model resolution, Brand B is the best choice for Mr. Ahmet.

Transformation. In the previous stages, Kerem calculated the daily average electricity consumption for Mr. Ahmet's house. To meet this consumption, he took into consideration the capacity of the panels to produce electricity according to their brands and sizes and calculated the number of panels required from each of them employing mathematical inequalities based on the highest performance. Thus, to make the most profitable choice, Kerem found that Mr. Ahmet can use 5 brand B panels by placing the panels on the roof as Picture 2.

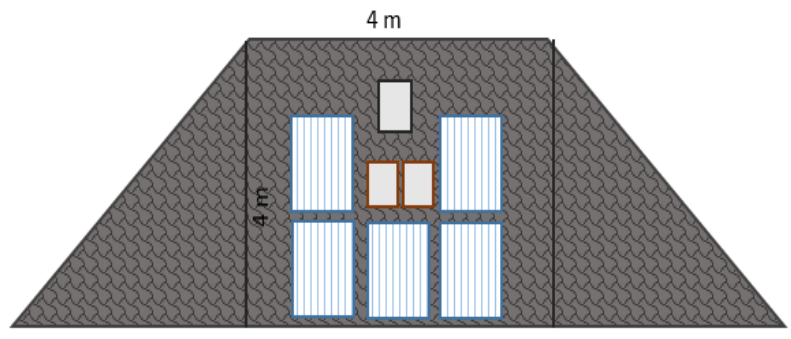

$4 \mathrm{~m}$

$12 \mathrm{~m}$

Picture 2 
Evaluation. Now, Kerem needs to evaluate his model and decide if solar panels are profitable for Mr. Ahmet or not. Based on Kerem's mathematical calculations, Mr. Ahmet will be able to make a profit after 12.5 years from laying 5 of brand B solar panels on the roof. Moreover, Kerem states that "in the meantime, the cost of electricity will raise and they will pay higher bills every month. So I think Mr. Ahmet will compensate for the cost of the bill much sooner. Since solar panels have an average full working life of 25 years, I think that Mr. Ahmet will have done a profitable job in the long run by laying solar panels on the roof of his house." Thus, based on Kerem's model and evaluation, Mr. Ahmet should build the solar panel system.

Report generation. Kerem writes a report about what he has done during the whole process of the IMM activity and what his decision is with justification.

\section{Discussion \& Conclusion}

STEM education aims to provide students with knowledge and skills in science, technology, mathematics, and engineering through interdisciplinary approaches. Mathematical modeling activities may have an important place in STEM education as a tool that provides this kind of opportunity to improve students' problem-solving skills in teaching and learning different subjects. Having an integrative approach to teach mathematics and science not only facilitates the development of students' motivation, engagement, and problem-solving skills in both disciplines but also aids students' ability to think critically and to uncover the relevance of concepts studied (Treacy \& O'Donoghue, 2014). The context in which the problem is presented plays a key role in providing meaningful learning for the students, as seen in the activity of Electricity from the Sun. When the IMM model is analyzed in-depth, it is clear that it embodies many of the characteristics which are recommended for integrating mathematics and science. Therefore, placing interdisciplinary mathematical modeling activities at the center of STEM education might allow a rich integration of mathematics with other disciplines by allowing students to understand the concepts of science and mathematics in real life and to use them effectively in the decision-making process.

In this paper, we provided a theoretical framework, Interdisciplinary Mathematical Modeling, to discuss how to integrate individual STEM disciplines. We specifically focused on the integration of mathematics and science subjects. The example of Electricity from the Sun was used to show how this framework might work in a classroom. As the hypothetical student's solution showed, IMM activities can be rich tasks that enable students to develop, synthesize, and apply knowledge with opportunities to? focus classroom inquiry. Since the IMM activities are based on a mathematical modeling approach, they are connected to realworld experience by their very nature. By engaging this kind of activity, as it is seen in the hypothetical example, students need to attend to both mathematics and science concepts to solve the problem. One important feature of IMM activities is that students are central to the process that gives them responsibility for their learning and a sense of ownership concerning what and how they learn both mathematics and science. This is crucial for 
having an effective integrated approach in STEM. Thus, we believe that using IMM activities to integrate STEM subjects by using real-life scenarios may have a positive impact on student attitudes and understanding of each discipline because it facilitates and complements learning and understanding within different disciplines rather than treating them as separate subjects. This integration is critical to motivate and engage students in meaningful learning (Wilhelm \& Walters, 2006; Furner \& Kumar, 2007). The IMM model aims to develop and improve specialized skills and knowledge within each discipline as well as making a connection across them by having an integrated approach.

Although this article describes an integrative model, to teach only mathematics and science to enhance students' learning in both disciplines, the IMM model can be used to teach all STEM subjects. Figure 3 presents the integration of all STEM subjects. Because IMM is a multi-disciplinary structure, it may not involve all disciplines in every activity. Having mathematics is required, but it can be mathematics and engineering, or mathematics and technology, or having all of three or four disciplines together. Thus, the approach presented here aims to integrate these four STEM disciplines into a coherent learning paradigm based on real-world applications, rather than as separate topics.

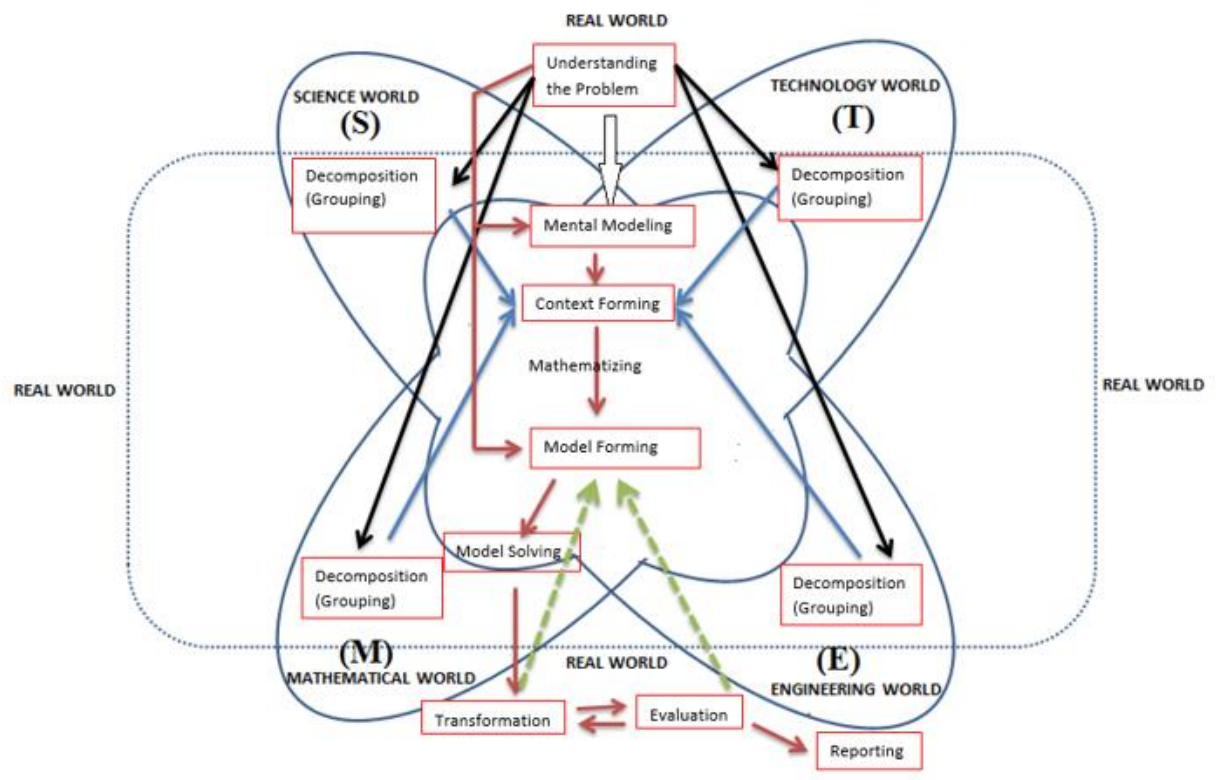

Figure 3. Interdisciplinary Mathematical Modeling [IMM] Process of STEM

When both IMM processes (IMM of Mathematics \& Science and IMM of STEM) are taken into consideration, it appears that there is no difference in the process steps and 
transitions between steps, and it only happens in the areas where the activity is related, which means that each corner that represents disciplines can be moved as needed. In other words, the IMM process can take place in all areas of the STEM approach, as well as in one or both of the other areas, where mathematics is necessary, depending on the structure of the activity and the area to which it relates. Although the components of these frameworks are presented linearly here, it is not a linear process, but an iterative process. Therefore, the framework is applied in iterative processes that enable learners to freely evaluate their thinking in a timely fashion and make the required changes in their approach.

As discussed above, the key feature of IMM activities in the STEM approach is to increase the transfer capacity of STEM-focused knowledge and skills to real-world scenarios by presenting problem situations in a real-world context. This also highlights that IMM activities have a critical place in the understanding of the role of mathematics in STEM. Designing interdisciplinary mathematical modeling activities may play a crucial role in integrating STEM disciplines as presented in our IMM framework. Yet, here we used a hypothetical student's answer to present our model, thus there is an important need to research if all stages in our theoretical framework somehow emerge in a randomly selected student or groups' solutions. In this respect, we believe it may be necessary to eliminate the deficiencies, if any, and revise the theoretical framework by examining the work of the real students. Besides, there is a need for more research to understand how this kind of activity can be integrated into textbooks and implemented in real classrooms and what the role of teachers are in applying these rich tasks.

\section{References}

Berry, J., \& Houston, K. (1995). Students using posters as a means of communication and assessment. Educational Studies in Mathematics, 29(1), 21-27.

Berry, M. R., Chalmers, C., \& Chandra, V. (2012). STEM futures and practice, can we teach STEM in a meaningful and integrated way. Paper presented at the 2nd International STEM in Education Conference, Beijing, China.

Blomhøj, M., \& Jensen, T. H. (2007). What's all the fuss about competencies?. In: Blum W., Galbraith P.L., Henn HW., Niss M. (eds), In Modelling and applications in mathematics education (pp. 45-56). Springer, Boston, MA.

Blum, W. (2011). Can modelling be taught and learnt? Some answers from empirical research. In: Kaiser G., Blum W., Borromeo Ferri R., Stillman G. (eds), In Trends in teaching and learning of mathematical modelling (pp. 15-30). Springer, Dordrecht.

Blum, W., \& Niss, M. (1991). Applied mathematical problem solving, modelling, applications, and links to other subjects-State, trends and issues in mathematics instruction. Educational Studies in Mathematics, 22(1), 37-68.

Borromeo-Ferri, R. (2006). Theoretical and empirical differentiations of phases in the modelling process. $Z D M, 38(2), 86-95$. 
Bowman, K. (2010). Background paper for the AQF Council on generic skills. Australian

Qualification Framework Council: Canberra, Australia. Erişim adresi:

https://s3.amazonaws.com/academia.edu.documents/34765959/Generic-skillsbackground-paper-FINAL.pdf

Bybee, R. W. (2013). The case for STEM education: Challenges and opportunities. Arlington, VA: NSTA Press.

Chan, J. K. (2001, June). A curriculum for the knowledge age: The Singapore approach. Paper presented at the eighth annual Curriculum Corporation Conference, Sydney, Australia.

National Governors Association Center for Best Practices \& Council of Chief State School Officers [CCSSM]. (2011). Common core state standards for mathematics. Washington, DC: Author.

Curriculum Planning and Development Division [CPDD]. (2006). Mathematics Syllabus. Singapore, Ministry of Education: CPDD.

Davison, D. M., Miller, K. W., \& Metheny, D. L. (1995). What does integration of science and mathematics really mean? School Science and Mathematics, 95(5), 226-230.

Doerr, H. M. (1997). Experiment, simulation and analysis: An integrated instructional approach to the concept of force. International Journal of Science Education, 19(3), 265-282.

English, L. D. (2017). Advancing elementary and middle school STEM education. International Journal of Science and Mathematics Education, 15(1), 5-24.

Fitzallen, N. (2015). STEM education: What does mathematics have to offer? In M. Marshman, V. Geiger, \& A. Bennison (Eds.), Mathematics education in the margins (Proceedings of the 38th annual conference of the Mathematics Education Research Group of Australasia), pp. 237-244. Sunshine Coast: MERGA.

Furner, J. M., \& Kumar, D. D. (2007). The mathematics and science integration argument: a stand for teacher education. Eurasia Journal Of Mathematics, Science \& Technology Education, 3(3), 185-189.

Galili, I. (2018). Physics and mathematics as interwoven disciplines in science education. Science \& Education, 27(1-2), 7-37.

Gravemeijer, K., Stephan, M., Julie, C., Lin, F. L., \& Ohtani, M. (2017). What mathematics education may prepare students for the society of the future? International Journal of Science and Mathematics Education, 15(1), 105-123.

Kaiser, G., \& Sriraman, B. (2006). A global survey of international perspectives on modelling in mathematics education. ZDM, 38(3), 302-310.

Kapur, J. N. (1982). The art of teaching the art of mathematical modelling. International Journal of Mathematical Education in Science and Technology, 13(2), 185-192.

Lawrenz, F., Gravemeijer, K., \& Stephan, M. (2017). Introduction to this special issue. International Journal of Science and Mathematics Education, 15(1), 1-4.

Lesh, R., \& Doerr, H. M. (2003). Foundations of a models and modeling perspective on mathematics teaching, learning, and problem solving. In R. Lesh, \& H. M. Doerr (Eds.), 
Beyond constructivism: Models and modeling perspectives on mathematics problem solving, learning, and teaching (pp. 3-33). Mahwah, NJ: Lawrence Erlbaum.

Marginson, S., Tytler, R., Freeman, B., \& Roberts, K. (2013). STEM: Country comparisons: International comparisons of science, technology, engineering and mathematics (STEM) education (Final report). Erişim adresi: http://dro.deakin.edu.au/eserv/DU:30059041/tytler-stemcountry-2013.pdf

Mason, J. (1988). Mason, J. (1988). Modelling: what do we really want pupils to learn? In D. Pimm (ed.), Mathematics, teachers, and children (pp. 201-215). London: Hodder and Stoughton.

McBride, J. W., \& Silverman, F. L. (1991). Integrating elementary/middle school science and mathematics. School Science and Mathematics, 91(7), 285-292.

Ministry of National Education [MoNE]. (2016). STEM eğitim raporu. Ankara: Yenilik ve Eğitim Teknolojileri Genel Müdürlüğü.

Ministry of National Education [MoNE]. (2018). The board of education, secondary school mathematics program (5th, 6th, 7th and 8th grade) curriculum. Retrieved February 20, 2018 from http://mufredat.meb.gov.tr/Programlar.aspx

Moore, T. J., \& Smith, K. A. (2014). Advancing the state of the art of STEM integration. Journal of STEM Education: Innovations and Research, 15(1), 5-10).

National Council of Teachers of Mathematics. (2000). Principles and standards for school mathematics. Reston, VA: Author.

Ng, K. E. D. (2011). Mathematical knowledge application and student difficulties in a design-based interdisciplinary project. In: Kaiser G., Blum W., Borromeo Ferri R., Stillman G. (eds), In Trends in teaching and learning of mathematical modelling (pp. 107-116). Springer, Dordrecht.

Niss, M. (1989). Aims and scope of applications and modelling in mathematics curricula. In Blum, W. et al. (eds.), Applications and modelling in learning and teaching mathematics, pp: (22-31). Horwood, Chicester, UK.

Ostler, E. (2012). 21st century STEM education: A tactical model for long-range success. International Journal of Applied Science and Technology, 2(1), 28-33.

Partnership for 21st Century Skills (2015). P21 framework definitions. Retrieved December 10 , 2016 from http://www.p21.org/storage/documents/docs/P21_Framework_Definitions_New_Logo 2015.pdf

Sanders, M. (2009). Integrative STEM education: Primer. The Technology Teacher, 68(4), 20-26.

Schmidt, W. H., \& Houang, R. T. (2007). Lack of Focus in the Mathematics Curriculum: Symptom or Cause. In Tom Loveless (Ed.), Lessons Learned: what international assessments tell us about math achievement, pp. 65-84. Washington: Brookings Institution Press.

Shaughnessy, J. M. (2013). Mathematics in a STEM context. Mathematics Teaching in the Middle School, 18(6), 324-324. 
Smith, J., \& Karr-Kidwell, P. J. (2000). The interdisciplinary curriculum: A literary review and a manual for administrators and teachers. Erişim adresi: http://www.eric.ed.gov/PDFS/ED443172.pdf

Treacy, P., \& O’Donoghue, J. (2014). Authentic integration: A model for integrating mathematics and science in the classroom. International Journal of Mathematical Education in Science and Technology, 45(5), 703-718.

Uhden, O., Karam, R., Pietrocola, M., \& Pospiech, G. (2012). Modelling mathematical reasoning in physics education. Science \& Education, 21(4), 485-506.

Verschaffel, L., Greer, B., \& De Corte, E. (2000). Making sense of word problems. Lisse: Swets \& Zeitlinger.

Wagner, T. (2014). The global achievement gap: why even our best schools don't teach the new survival skills our children need-and what we can do about it. New York: Basic Books.

Wilhelm, J. A., \& Walters, K. L. (2006). Pre-service mathematics teachers become full participants in inquiry investigations. International Journal of Mathematical Education in Science and Technology, 37(7), 793-804.

\section{Appendix A.}

\section{ELECTRICITY FROM THE SUN ACTIVITY}

\section{Warming up questions before the class time:}

- For what purposes can we use solar energy?

- Is it possible for you to convert solar energy into electricity? (If the answer is "yes") How?

\section{The Solar Energy}

With renewable energy sources becoming more important in recent years, solar energy systems, which are an environmentally clean energy source, have started to be used frequently in the production of electricity. Solar energy systems are the systems that turn solar energy into electricity. The full capacity working life of a solar panel is 25 years on average. At the end of this period, it continues to work at $75 \%$ efficiency. To give an example of the amount of electricity produced by panels;

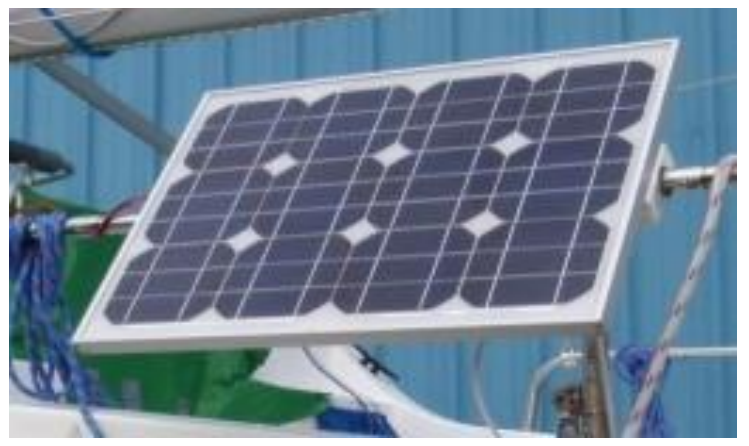

As shown in the figure, a 200 Watt solar energy panel with a size of $70 \mathrm{~cm} \times 150 \mathrm{~cm}$ takes an average of 6 hours of sunshine per day. In this case, the amount of electricity produced per day is $200 \times 6=1200$ watts. 


$$
\text { Power }=\frac{\text { Energy }}{\text { Time }}
$$

Watt is the electrical power unit. Electrical power is the amount of electricity consumed per unit time. The unit of power is watt (w), the unit of energy is joule, the unit of time is assumed to be seconds. The amount of electrical power we spend on household appliances (fridge, oven, etc.), electronics (electricity vacuum, television, etc.) we use in daily life is expressed in watts. Generally, the number written on the vacuum cleaners shows the amount of electrical power that the vacuum consumes in an hour when the vacuum is running. For example, a $1,500 \mathrm{~W}$ cleaner consumes $1.5 \mathrm{~kW}$ of power per hour. In the same way, a 20 -watt bulb that we use in our homes consumes $0.02 \mathrm{~kW}$ per hour.

Electric bills are also calculated over the kilowatt used per month.

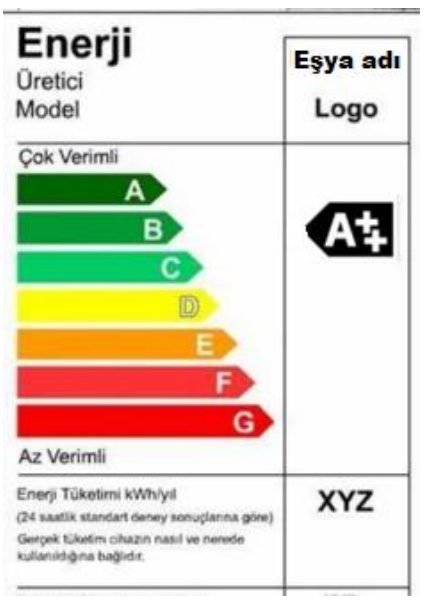

\section{Warm up Activity:}

- By examining the vacuum cleaner in your home, find the amount of energy that it spends in one second, one minute and one hour.

- Note the unit on top of the electricity meter in your home.

- Write down which consumer class your electronics belong to in your home.

\section{The Problem}

Mr. Ahmet wants to place solar panels on the roof of his house and he has decided to spend a total of $8500 \mathrm{TL}$ for the hardware (inverter, battery, steel construction) necessary for the operation of the panels. However, to determine how many panels will be placed on the roof, the amount of electricity used at home must be determined. Some parts of the house have a chandelier and some have lamps. The number of lamps on each chandelier is 3. Each lamp is $20 \mathrm{wh}$. Information on the number of chandeliers and lamps in the house sections and the electrical power of the electronic items used are as follows: 


\begin{tabular}{|c|c|c|c|c|c|}
\hline $\begin{array}{l}\text { Home } \\
\text { Section }\end{array}$ & $\begin{array}{l}\text { Chandelier / } \\
\text { Number of } \\
\text { lamps }\end{array}$ & $\begin{array}{l}\text { Home } \\
\text { Section }\end{array}$ & $\begin{array}{l}\text { Chandelier / } \\
\text { Number of } \\
\text { lamps }\end{array}$ & Electronic stuff & $\begin{array}{l}\text { Electrical } \\
\text { Power } \\
\text { (wh) }\end{array}$ \\
\hline $\begin{array}{l}\text { Seating } \\
\text { Room }\end{array}$ & 1 chandelier & Kids Room & 1 chandelier & A refrigerator & 40 \\
\hline Hall & 2 chandelier & Corridor & 2 lamps & $\begin{array}{l}\text { Washing } \\
\text { machine }\end{array}$ & 800 \\
\hline Kitchen & 1 chandelier & Toilet & 2 lamps & Dishwasher & 1250 \\
\hline \multirow[t]{6}{*}{ Bedroom } & 1 chandelier & Bathroom & 2 lamps & Vacuum cleaner & 2000 \\
\hline & & & & Television & 150 \\
\hline & & & & Bakery & 2000 \\
\hline & & & & Hairdryer & 2000 \\
\hline & & & & Iron & 2800 \\
\hline & & & & Computer & 350 \\
\hline
\end{tabular}

When the solar panels that will produce the amount of electricity needed for the house are laid on the roof, it is necessary to observe some rules. The solar panels should be placed on the roof so that no panel space is left out of the roof. The distance between the panels must be at least $20 \mathrm{~cm}$ and it is possible to lay the panels in different sizes on the roof. Information about the sizes and prices of the panels are as follows:

\begin{tabular}{|l|l|l|l|}
\hline Solar Panel ** & $\begin{array}{c}\text { Average Power Generated in 1 } \\
\text { Hour (Watts) }\end{array}$ & Dimensions & Price (TL) \\
\hline Model A & 300 watt & $1 \mathrm{~m} \mathrm{x} \mathrm{m}$ & $1250 \mathrm{TL}$ \\
\hline Model B & 200 watt & $1 \mathrm{~m} \times 1,5 \mathrm{~m}$ & $800 \mathrm{TL}$ \\
\hline Model C & 45 watt & $55 \mathrm{cmx} 65 \mathrm{~cm}$ & $215 \mathrm{TL}$ \\
\hline
\end{tabular}

** The solar panels have a built-in electrical storage feature.

In the settlement where the residence is located, it is known that the solar utilization periods of the panels are 6 hours in winter and 12 hours in summer. Mr. Ahmet wants to build solar panels in a way that can match his electricity needs and at a reasonable cost. Panels can store the electricity produced. Create a model that shows how Mr. Ahmet can place the solar panels that can meet his electricity needs at the roof, at an affordable cost, and show in detail how you did it. Do you think that Mr. Ahmet should build with solar panels to cover the electricity cost of the house? (Note: The unit price of the bill is 0.2 lira, 35 lira tax) (Energy lost during the conversion of solar energy to electrical energy will be ignored). 
APPENDIX B.

\section{HYPOTHETICAL STUDENT'S ANSWER TO THE PROBLEM}

Understanding the problem: Mr. Ahmet will lay solar panels on the roof of his house to cover his house's electricity costs. I want to calculate the amount of electricity Mr. Ahmet wants to find the most saving solar panel model.

Decomposition/Grouping: First of all I have to find out how many kW electricity Mr. Ahmet has spent in a given time period. I need to determine how many kilowatts of electricity needed for electronic goods and lamps on the table in one hour. For that reason, I have to determine how many electrical appliances used and how many lamps are used in a room. I can calculate the total electricity cost by multiplying the working hours of appliances and lamps by the amount of electricity consumed in one hour.

Creating a mental model: I think that Mr. Ahmet lives with his family in this house because he wants to use solar panels to cover his electricity expenses. If he lived alone, electricity costs would not have been so high and Mr. Ahmet would not think of laying a solar panel on his roof. I think it's a family of 5, so I'll figure out how much electricity they're spending in a week and I'll find a monthly electricity bill for the house. Then, I will find solar panels with a low-cost performance that will meet Mr. Ahmet's electricity costs. Because the days are shorter in winter, the length of use of household lamps will be longer than in summer months. There is no change in the use of electrical appliances. I will determine the average lifetime of lamps and electronic items, considering both the winter and summer months.

Mathematizing: The average amount of electricity consumed weekly by the lamps during the year and the average weekly usage times of the electronic household items and the amount of electricity consumed are shown in the following tables:

\begin{tabular}{|l|l|l|l|}
\hline Home Section & $\begin{array}{c}\text { Chandelier / } \\
\text { Number of lamps }\end{array}$ & $\begin{array}{c}\text { Average } \\
\text { weekly } \\
\text { usage time } \\
\text { (hours) }\end{array}$ & $\begin{array}{c}\text { Amount of electricity consumed } \\
\text { (wh) } \\
\text { (Number of lamps x Power x } \\
\text { Operating time) }\end{array}$ \\
\hline Seating Room & 1 chandelier & 45 & $3 \times 20 \times 45=2700$ \\
\hline Hall & 2 chandelier & 4 & $6 \times 20 \times 4=480$ \\
\hline Kitchen & 1 chandelier & 21 & $3 \times 20 \times 21=1260$ \\
\hline Kids Room & 1 chandelier & 30 & $3 \times 20 \times 30=1800$ \\
\hline Corridor & 2 lamps & 45 & $2 \times 20 \times 45=1800$ \\
\hline Toilet & 2 lamps & 10 & $2 \times 20 \times 10=400$ \\
\hline Bathroom & 2 lamps & 12 & $2 \times 20 \times 12=480$ \\
\hline & & Total & 8920 \\
\hline
\end{tabular}




\begin{tabular}{|l|l|l|l|}
\hline \multicolumn{1}{|c|}{ Electronic stuff } & $\begin{array}{c}\text { Electrical Power } \\
\text { (wh) }\end{array}$ & $\begin{array}{c}\text { Average weekly usage time } \\
\text { (hours) } \\
\text { (Days x Usage time) }\end{array}$ & \multicolumn{1}{|c|}{$\begin{array}{c}\text { Amount of } \\
\text { electricity } \\
\text { consumed (wh) }\end{array}$} \\
\hline A refrigerator & 40 & $7 \times 24=168$ & 6720 \\
\hline Washing machine & 800 & $3 \times 3=9$ & 7200 \\
\hline Dishwasher & 1250 & $3 \times 2=6$ & 7500 \\
\hline Vacuum cleaner & 2000 & $2 \times 1.5=3$ & 6000 \\
\hline Television & 150 & $6 \times 4=24$ & 3600 \\
\hline Bakery & 2000 & $3 \times 1=3$ & 6000 \\
\hline Hairdryer & 2000 & $4 \times 0.5=2$ & 4000 \\
\hline Iron & 2800 & $2 \times 1=2$ & 5600 \\
\hline Computer & 350 & $7 \times 2=14$ & 4900 \\
\hline & & Total & 51520 \\
\hline
\end{tabular}

Mr. Ahmet and his family spend an average of $8920+51520=60440$ watts of electricity in a week. This is 60000 watts $=60 \mathrm{~kW}$. Then the average monthly electricity usage (4 weeks) is $60 \mathrm{x} 4=$ $240 \mathrm{~kW}$. The daily electricity need is $60 / 7=8.57 \mathrm{~kW}$. Now I will choose the most suitable solar panel for the roof.

Model Forming: Since the shape of the roof of Mr. Ahmet's house is not mentioned, I am going to layout the solar panels thinking that the roof is a hip roof. For solar energy to be stored at the highest level, the rays of the sun must come at the right angle. If the panel is fixed to the roof, it can store energy at certain times of the day. For this, I am going to use moving panes to raise the level of solar utilization.

The picture represents Mr. Ahmet's house. I think that solar panels need to be located on the south side of the roof for efficient operation. Because the solar energies always look south (Transformation). I need to place the panels on the trapezoidal surface seen in the picture. If this area is not enough, I can place panels in the triangular section of the roof. In the problem, A, B and C brand solar panels are said to be used together, but I think solar panels of different sizes are ugly on the roof. For that reason, I prefer to use a single panel. From my experience, I can say that panels are usually the same size on the roof of houses.

Model Forming: The south side of the roof looks as in the following picture. By estimating the door and window dimensions of the house, I thought that the lower base length of the roof would be

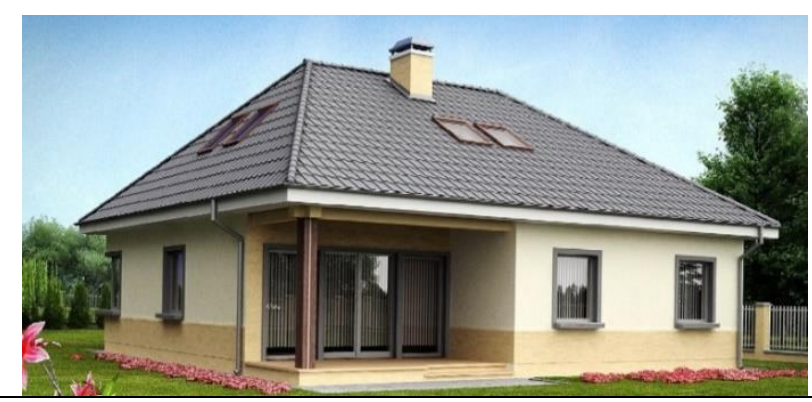
$12 \mathrm{~m}$ on average and the upper base length would be $4 \mathrm{~m}$. I did a little research on the internet to determine the slope of the roof, and I figured out that roof slopes could be $30^{\circ}, 45^{\circ}$, and $60^{\circ}$. I decided that the roof of Mr. Ahmet's house had a $45^{\circ}$ slope. After deciding on the inclination of the roof, I chose the chimney and two small windows. I 
assumed that the short side of the chimney is $50 \mathrm{~cm}$ and the long side is $75 \mathrm{~cm}$. I took the size of the small windows as $50 \mathrm{~cm}$ x $60 \mathrm{~cm}$. I have to place the solar panels in the area outside these areas.

Solar utilization time is 6 hours in winter; we agreed it was 12 hours in the summer. In this case, an average of $(6+12) / 2=9$ hours a day can be utilized within a year.

The average amount of electricity produced by panels per day: I have calculated above that the

Model A 300 x 9= 2700 watt,

Model B 200 x $9=1800$ watt and

Model C 45 x $9=405$ watt amount of electricity used by Mr. Ahmet and his family is $8.57 \mathrm{~kW}=8570$ watts. Then I must first find out how many (the minimum number) solar panels I need to use.

\section{$\mathrm{x}: 2700 \mathrm{x}>8570$ if it is A brand solar panel}

$\mathrm{y}: 1800 \mathrm{y}>8570$ if it is B brand solar panel

z: 405 z> 8570 if it is C brand solar panel.

Model resolution: $\mathrm{x}$ must be at least 4; y must be at least 5; z must be at least 22. Looking at the areas of the solar panels, it is seen that the solar panels in these numbers can easily be laid on the roof:

A brand: Since $1 \mathrm{~m} \times 2 \mathrm{~m}=2 \mathrm{~m}^{2}, 2 \times 4=8 \mathrm{~m}^{2}$ area needed

B brand: Since $1 \mathrm{~m} \times 1.5 \mathrm{~m}=1.5 \mathrm{~m}^{2}, 1.5 \times 5=7.5 \mathrm{~m}^{2}$ area needed

C brand: Since $0.55 \mathrm{~m}$ x $0.65 \mathrm{~m}=0.3575 \mathrm{~m}^{2}, 0.3575 \times 22=7.865 \mathrm{~m}^{2}$ area needed.

I can find the solar panel with the highest performance by comparing the price of solar panels, the size and the amount of power produced in one hour. For example, for an area of $6 \mathrm{~m} 2$, we can use 3 of brand A solar panels or 4 of brand B solar panels. In this case, the cost of brand A is $1250 \times 3=3750$ TL; while the cost of brand B is $800 \times 4=3200 \mathrm{TL}$. When you look at the amount of power they produce, Brand A produces 300 × $3=900$ watts while brand B produces 200 x $4=800$ watts of power per hour. In this case, the cost to produce 1 watt of electricity from brand A solar panel $(3750 / 900=$ $4.16 \mathrm{TL})$ is more than brand $\mathrm{B}$ solar panel $(3200 / 800=4 \mathrm{TL})$. This means that the performance of the brand B solar panel is higher than brand A. A similar calculation shows that the A brand is more affordable than the $\mathrm{C}$ brand. Thus, we can sort the panels by $\mathrm{B}>\mathrm{A}>\mathrm{C}$., In that case, it would be more

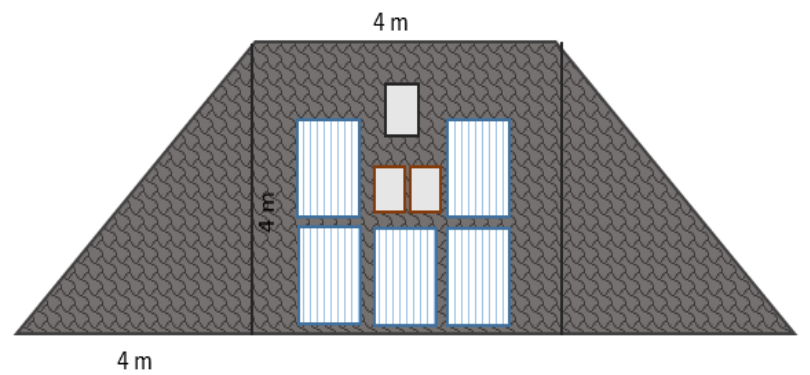

$12 \mathrm{~m}$ advantageous to use the $\mathrm{B}$ brand panel.

Transformation: To make the most profitable choice, Mr. Ahmet can use brand B panels. Placing the panels on the roof can be done as the picture.

Evaluation: The total cost of 5 brand B solar panels that $\mathrm{Mr}$. Ahmet needs is $800 \times 5=4000$ TL. To produce electricity, Mr. 
Ahmet spent $8500 \mathrm{TL}$ on the machines and equipment required besides the panels. When this cost is taken into account, Mr. Ahmet will have to spend $4000+8500=12500 \mathrm{TL}$. Mr. Ahmet and his family spend an average of $240 \mathrm{~kW}$ per month. According to this, the monthly electricity bill is $240 \mathrm{x}$ $0.2+35=83$ TL. I can find out how long the solar panel will compensate for the cost of the bill when the total cost is:

$$
\frac{\text { Cost }}{\text { Bill }}=\frac{12500}{83}=150 \text { months }
$$

Mr. Ahmet will be able to earn after 12.5 years from laying 5 of brand B solar panels on the roof. In the meantime, the cost of electricity will raise and they will pay higher bills every month. So I think Mr. Ahmet will compensate for the cost of the bill much sooner. Since solar panels have an average full working life of 25 years, I think that Mr. Ahmet will have done a profitable job in the long run by laying solar panels on the roof of his house.

Report generation: In the problem, Mr. Ahmet stated that he wanted to use the solar panel to cover the electricity costs of his house, but he could not decide which solar panel to use and which brand of solar panels would be more suitable to build. As I was not informed about Mr. Ahmet's family and the house he was living in, I made some assumptions and imagined that a family of five would live in a house like above (I've decided on the roof type and slope). I calculated the daily average electricity needs of his family because the solar panels gave the average power they produced in one day. Then I set the area where the solar panels will be built. Since Mr. Ahmet did not want to store or sell the electricity produced by the panels, the needed panels should be the least number of needed. I have calculated the minimum number of panels needed from each brand for the area on the roof that I have set for this. I found that electricity costs could be met by using at least 4 of brand A solar panels or at least 5 of brand B solar panels or at least 22 of brand C solar panels. I looked to see if it had enough space for each option, and I saw that the area of the roof outside the chimneys and windows as appropriate. I compared the performances of the solar panels to decide which brands would be more appropriate. When comparing the performances, I took into account the cost, size and average power generated by solar panels. I saw that the solar panel brand with the best performance was brand $\mathrm{B}(\mathrm{B}>\mathrm{A}>\mathrm{C})$. I placed 5 of brand $\mathrm{B}$ solar panels on the roof as above. I calculated the cost as $800 \mathrm{TL}$ x $5=4000 \mathrm{TL}$. To produce electricity, Mr. Ahmet spent $8500 \mathrm{TL}$ on the machines and equipment required besides the panels. In this case, the total cost of solar panels will be $8500 \mathrm{TL}+$ $4000 \mathrm{TL}=12500 \mathrm{TL}$. Mr. Ahmet and his family's monthly electricity bill is $83 \mathrm{TL}$. According to this, I first thought that Mr. Ahmet would compensate for the cost of his bill after 12.5 years by dividing the total cost of the solar panels to the monthly amount of bill. However, when thinking that his electric bills would not remain constant and would rise over time, I claimed that he compensates for the cost of the bill less than 12.5 years. Since solar panels have an average full working life of 25 years, I think that Mr. Ahmet will have done a profitable job in the long run by laying solar panels on the roof of his house. 